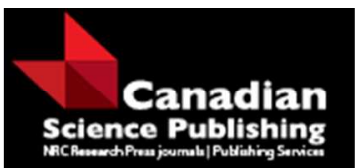

Canadian Journal of Forest Research

Revue canadienne de recherche forestière

\title{
Assisted lodgepole pine regeneration on reclamation sites using logging slash as both a mulch and natural seed source
}

\begin{tabular}{|r|l|}
\hline Journal: & Canadian Journal of Forest Research \\
\hline Manuscript ID & cjfr-2016-0157.R1 \\
\hline Manuscript Type: & Article \\
\hline Date Submitted by the Author: & 24-Jun-2016 \\
\hline Complete List of Authors: & $\begin{array}{l}\text { Cirelli, Damián; University of Alberta, Renewable Resources } \\
\text { Vinge, Tim; Alberta Government } \\
\text { Lieffers, Victor; U of Alberta, }\end{array}$ \\
\hline Keyword: & mulch, regeneration, reclamation, recruitment, lodgepole pine \\
\hline & \\
\hline
\end{tabular}

SCHOLARONE ${ }^{\text {M }}$

Manuscripts 
1 Assisted lodgepole pine regeneration on reclamation sites using logging slash as both a mulch and natural seed source

$4 \quad{ }^{1}$ Department of Renewable Resources, University of Alberta, Edmonton, AB, Canada

$5 \quad{ }^{2}$ Alberta Environment and Parks, Edmonton, Alberta. E-mail: tim.vinge@gov.ab.ca

$6 \quad{ }^{3}$ E-mail: vic.lieffers@ualberta.ca

$7 \quad$ *Corresponding author e-mail: cirelli@ualberta.ca 
9 Abstract

10 In this study we tested the efficacy of establishing lodgepole pine (Pinus contorta Dougl.) from

11 seed using woody mulch produced from slashed tree tops from a pine harvesting site; this mulch

12 contained the closed serotinous cones of the lodgepole pine. Mulch was spread on prepared

13 reclamation sites at $0,1,3$ and $5 \mathrm{~cm}$ depth. Broadcast seeding of pine was also done at 0 and 1

$14 \mathrm{~cm}$ of mulch depth. Mulch cover that was $1 \mathrm{~cm}$ thick was the preferred treatment as it produced

1517,000 seedlings $\mathrm{ha}^{-1}$ by year 3 after treatment while being similar in seedling density to the 3

16 and $5 \mathrm{~cm}$ treatments. When 50,000 seeds $\mathrm{ha}^{-1}$ were added, seedling density went up more on the

17 sites with $1 \mathrm{~cm}$ of mulch than the $0 \mathrm{~cm}$ sites. Soil temperature was lower and temperature

18 extremes were reduced under the mulch layer compared to the control plot. The plots with $1 \mathrm{~cm}$

19 mulch also had higher soil moisture in the mineral layer than the plots with $0 \mathrm{~cm}$ of mulch. A

20 thin layer of woody mulch therefore, provided both a source of pine seed and the covering of the

21 ground provided a more benign environment for the establishment of pine germinants.

22 Keywords: lodgepole pine, mulch, reclamation, regeneration, recruitment. 


\section{Introduction}

25 Lodgepole pine (Pinus contorta Dougl.) populations dominate much of the landscape in the

26 lower foothills ecoregion of Alberta (Ecological Stratification Working Group 1996), where they

27 are subjected to multiple forms of disturbance including timber harvesting, mountain pine beetle

28 outbreaks, and oil and gas exploration. Abandoned roads, drilling pads, and other severely

29 disturbed sites in the boreal and montane forests of Alberta regularly need to be restored to pine

30 forests in order to meet regulatory requirements of woody vegetation on reclaimed forest sites

31 (ESRD 2013). This is particularly important for recovering biodiversity as well as habitat for

32 sensitive wildlife species (Eldridge et al. 2012). The conditions left by such human activity

33 however, are at best sub-optimal for the successful establishment of lodgepole pine and other

34 conifers, particularly when bare mineral soil is exposed (Wang et al. 2005; Kemball et al. 2006);

35 without adequate site preparation many conifer germinants would fail (Lanini and Radosevich 36 1986).

37 Some of the advantages of re-contouring the subsoil along with returning the topsoil to the 38 surface have been well documented for disturbed sites such as drill pads (Campbell et al. 2008; 39 Larney and Angers 2012). The de-compaction of the surface layers is also necessary in many 40 cases to promote soil aeration and root penetration (Startsev and McNabb 2009). Additionally, 41 there is also a benefit to adding organic soil amendments in some circumstances (Larney and 42 Angers 2012). All these practices can improve growing conditions by reducing soil strength and 43 increasing soil temperature, along with improving water holding capacity for planted seedlings 44 (Bulmer et al. 2007). They can also be effective in reducing competition from nutrient45 demanding weeds, for example when C-rich sawdust is added (Speigelberger et al. 2009). In 
46 some cases this has resulted in increased growth rates of planted trees (Sanborn et al. 2004)

47 while in other cases only small changes have been observed (Bulmer et al. 2008).

48 As a serotinous pine species, lodgepole pine trees keep large amounts of viable seed in closed 49 cones in the canopy, with virtually no seedbank available in the forest floor (Corns and La Roi 50 1976). Greater than 20 years of closed cones accumulate in the crown of the trees, containing up 51 to $30 \times 10^{6}$ seeds ha $^{-1}$ (Teste et al. 2011a). These cones are typically opened by the heat of 52 wildfire, which is the main disturbance associated with stand regeneration for this species (Muir 53 and Lotan 1985). The resin bonds sealing the cone scales soften and let the scales separate when 54 exposed to temperatures higher than $45{ }^{\circ} \mathrm{C}$ (Perry and Lotan 1977). Forest managers have 55 scarified sites using drags made of ship anchor chains to both reduce the thickness of duff to 56 create seed beds, and to open the cones of the serotinous pines (Landhäusser 2009). The heavy 57 drags reposition the cones close to the ground surface, where temperatures may sometimes reach $5850^{\circ} \mathrm{C}$, which is warm enough to open the cone scales.

59 Lodgepole pine regeneration on bare reclamation sites is limited primarily by a deficiency of 60 seeds (Corns and La Roi 1976), but fully open sites also have easy access to feeding animals, 61 intense radiation, rapid drying of the surface layer, and micro-erosion liable to shift the 62 germinating seeds before effective root anchoring (Elmarsdottir et al. 2003). The lack of a seed 63 bank may be easily overcome by broadcasting seed, but the poor habitat of these exposed sites 64 can make this practice ineffective. Woody mulch layers could alleviate some of these concerns 65 on reclamation sites but they have not been tested to determine their influence on conifer tree 66 regeneration. In this study we examined the establishment of lodgepole pine (Pinus contorta 
67 Dougl.) using mulch produced from logging slash that would be normally burned as waste at the 68 logging site.

69 The objective of this work was to assess the effectiveness of rough-chipped mulch from 70 lodgepole pine logging slash, applied at different depths, as an assisted-natural regeneration 71 strategy for lodgepole pine. This was compared to broadcast spreading of pine seed, with and 72 without a thin layer of mulch. We also tested if there are regeneration benefits of tilling-in larger 73 quantities of pine mulch into the soil. Soil temperature, moisture and nutrient availability were 74 also assessed in relation to mulch thickness.

\section{Methods}

76 Six drill pads (natural gas wells) about 1 ha in size were constructed in 2009 and 2010 in the

77 Upper Foothills zone of the boreal forest on sandy clay loam in Brunisolic and Orthic Gray

78 Luvisols of the upper foothills ecoregion - specifically 'd' and 'e' ecosites (Beckingham et al.

79 1996). In the construction phase, the topsoil consisting of the $\mathrm{L}, \mathrm{F}, \mathrm{H}$, and $\mathrm{A}$ soil horizons was 80 stripped and stockpiled off the site. The average depth of the topsoil before removal was $10 \mathrm{~cm}$, 81 across all sites. The pads were leveled and drilled and a production facility was established in the 82 centre of the pad. In August of 2011 , the outer ring of each pad ( $2 / 3$ of the pad area) was re83 contoured with subsoil as much as possible. The stored mixed topsoil was spread back onto this 84 outer ring and this area was disked to $40 \mathrm{~cm}$ with a breaking disc to alleviate soil compaction. 85 Some amount of mixing of the topsoil and the subsoil took place as a result of disking. In 86 October of 2011 the area around each active well installation was subdivided into 8 treatment 87 plots, each plot $200 \mathrm{~m}^{2}$ in area $(10 \times 20 \mathrm{~m})$. The plots were given the combinations of treatments 88 listed in Table 1. 
89 Woody debris for mulching was obtained from local forestry harvesting operations in areas 90 dominated by lodgepole pine. Whole trees were skidded to the roadside where a processor 91 removed tops and branches containing many closed cones of lodgepole pine. This slash was 92 piled and then mulched with a Peterson 4710B horizontal grinder (Peterson Pacific Corp, 93 Eugene, Oregon, U.S.A.). The chipping screens were removed from the grinder that would 94 otherwise have produced uniformly small chips. This resulted in more desirable irregular pieces 95 of debris that were between 1 and $4 \mathrm{~cm}$ in width and 2 to $15 \mathrm{~cm}$ in length, while mostly less than $96 \quad 1.5 \mathrm{~cm}$ thick. The debris contained many completely intact and partially shattered cones of the 97 serotinous lodgepole pine which was the expected outcome of the chipper screens removal (as 98 opposed to having entirely shattered cones).

99 The coarse mulch was applied with a manure spreader after tests were done to determine the speed of travel necessary to produce the treatment depths: 1, 3 and $5 \mathrm{~cm}$ of mulch as outlined in

101 Table 1. The mulch depths corresponded to mulch material wet weights of 3.32, 9.96, and 16.6

$102 \mathrm{~kg} \mathrm{~m}^{-2}$ for 1,3 , and $5 \mathrm{~cm}$ respectively (Table 1 ). The control treatment consisted of the spreader 103 being driven on the plots without producing output ( $0 \mathrm{~cm}$ of mulch). Additional plots with 3 or 5 $104 \mathrm{~cm}$ of mulch were disked after application such that the mulch was partly incorporated into the 105 soil. Some of the plots were also supplemented with lodgepole pine seed from a local source. 106 The supplementary seeding treatment was applied during the first week of May 2012 (i.e. after 107 mulch had been applied) using a cyclone seeder at walking speed that was calibrated to deliver $108 \sim 50,000$ viable seeds per hectare. This allowed a period of natural cold-wet stratification before 109 normal germination in June. 
110 Temperature data loggers $\left(\mathrm{HOBO}^{\circledR}\right.$, Onset, Cape Cod, Massachusetts, United States of America) 111 were buried at $10 \mathrm{~cm}$ from the surface of the soil on June $23^{\text {rd }}$ of 2012 and removed on 112 September $12^{\text {th }}$ of the same year. On the same days, ion exchange probes (PRS ${ }^{\circledR}$ probes, Western 113 Ag, Saskatoon, Saskatchewan, Canada) were installed (and removed) at an average depth of 5 $114 \mathrm{~cm}$ into the mineral soil. One ion exchange probe per plot was used, including plots where mulch 115 was incorporated. Both temperature and ion exchange probes were placed approximately at the 116 centre of each plot.

117 Seedlings counts were made in mid-August of 2013 and 2014 inside 10 circular sampling plots 118 within each treatment plot; each sampling plot being $2 \mathrm{~m}^{2}$ in area. The frequency of sampling 119 plots with at least one seedling was also assessed as a measurement of distribution (converted to 120 percent stocking). Soil samples of the top 10 to $15 \mathrm{~cm}$, excluding mulch, were collected and 121 bagged on August $27^{\text {th }}, 2014$. Soil water content was determined gravimetrically by weighing 122 before and after oven-drying the samples at $70{ }^{\circ} \mathrm{C}$ and verifying constant dry weight. Regional 123 precipitation at Grande Prairie was 4.7\% below normal for April to September in 2012, 15.0\% 124 below normal in 2013, and 25\% below normal in 2014 (Government of Canada 2015).

125 Statistical analyses were performed in R version 3.2.3 "Wooden Christmas-Tree” (R Core Team 126 2015) on a Linux platform. All the functions used to perform data calculations and statistical 127 analyses were from the included packages in the base $\mathrm{R}$ installation. The data were analyzed as 128 three separate experiments. Experiment 1 tested the effects of mulch depth on seedling 129 establishment success $(0,1,3$ and $5 \mathrm{~cm}$ depth) and it was analysed with a factorial one-way 130 ANOVA. Multiple comparisons were done using Tukey's test. Experiment 2 tested whether there was a benefit to supplementing the natural seed supply in control plots $(0 \mathrm{~cm}$ of mulch $)$ and 
132 in plots with a shallow layer of mulch $(1 \mathrm{~cm})$. A $2 \times 2$ factorial ANOVA was used to analyse 133 experiment 2. The third and final experiment tested the effects of heavy addition of mulch 134 without seed supplementation and the possible benefits of tilling the mulch into the soil (3 and 5 $135 \mathrm{~cm}$ of mulch with and without tilling) and compared to plots where mulch had not been 136 incorporated using a 2-way factorial ANOVA. In addition, the effect of mulch depth on soil 137 nutrient levels was also analysed as a one-way factorial design. All ANOVA tables are combined 138 in Table 2. Prior each analysis, boxplots were used to visually compare the variance between 139 treatments and a formal Bartlett's test was conducted to corroborate homogeneity. Normal Q-Q 140 plots were used to corroborate that the residuals followed a normal distribution. Data 141 transformation was not necessary in any case.

\section{Results}

143 Seedling density was nearly 10 times higher in plots with cone-bearing mulch cover than in plots

144 without cover $(\mathrm{p}<0.05)$. However, plots with no cover seemed to continue recruitment into the 145 third year of treatment, whereas in plots with mulch there was a net mortality rate of $14 \%$ on 146 average between the second and third years. There were no significant differences in seedling 147 density among mulch treatments, with a combined average of 18,000 seedlings ha ${ }^{-1}$ in the second 148 year (Fig. 1). Seeding improved seedling density (seeding effect $p<<0.01$ ) and there was benefit 149 of the addition of $1 \mathrm{~cm}$ of mulch (mulch effect $\mathrm{p}<<0.01$ ). The benefit of adding seed, however, 150 was larger in the $1 \mathrm{~cm}$ mulch (seeding $\times$ mulch interaction $\mathrm{p} \approx 0.07$ ); here seeding into cone151 bearing mulch increased density to 27,000 seedlings ha ${ }^{-1}$ (Fig. 2), an increase of $\sim 10,000$ 152 seedlings vs. $\sim 5000$ increase by seeding onto bare soil. Tilling-in the mulch resulted in 3,000 153 seedlings ha ${ }^{-1}$ (data not shown) and was comparable to the unseeded control plot. 
154 The frequency of the $2 \mathrm{~m}^{2}$ plots with pine seedlings (i.e. stocking) tended to be higher in plots 155 with $1 \mathrm{~cm}$ of mulch than in plots without mulch $(\mathrm{p}<0.05$, Fig. 3). However, the sites with 3 and $1565 \mathrm{~cm}$ of cone-bearing mulch were not significantly different from the non-covered plots albeit 157 showing higher frequency. As there was distinct clustering of seedlings around some of the 158 cones, stocking was not always related to overall seedling density.

159 Total soil exchangeable $\mathrm{N}$ levels were not significantly different among treatments with mulch 160 added to the surface. Ammonium levels however, were significantly higher in plots with 3 and 5 $161 \mathrm{~cm}$ of surface mulch compared with plots without cover $(\mathrm{p}<0.05)$. Plots with $1 \mathrm{~cm}$ of mulch 162 also tended to have higher $\mathrm{NH}_{4}{ }^{+}$levels than bare plots, but the difference was not significant 163 (Table 3). Exchangeable Fe was significantly higher in plots with greater mulch cover but Fe was 164 reduced when chips were tilled into the mineral soil. Tilling reduced the amount of $\mathrm{NH}_{4}^{+}(\mathrm{p}<$ 165 0.05), and $\mathrm{P}$ while other nutrients were mostly unchanged (Table 3).

166 Soil temperature and soil moisture were affected by the presence of surface mulch. Daily mean 167 temperatures of soil during summer were $14.4{ }^{\circ} \mathrm{C}$ in the plots with mulch cover and $16.0{ }^{\circ} \mathrm{C}$ in 168 non-covered plots (Fig. 4). This difference was statistically significant between $0 \mathrm{~cm}$ plots and 169 the 1, 3, and $5 \mathrm{~cm}$ plots combined but there were no differences among the mulched plots $(\mathrm{p}<$ 170 0.05). Daily thermal amplitude was also markedly lower in the mulch treatments with an average 171 of $4.0^{\circ} \mathrm{C}$ compared to $8.2^{\circ} \mathrm{C}$ in uncovered plots $(\mathrm{p}<0.05)$. Soil water content was higher in plots 172 with mulch than in plots without mulch $(\mathrm{p}=0.03)$, without major differences among mulch 173 treatments (Fig. 5).

174 We performed regression analyses on the seedling density response to soil temperature and to 175 each of the macronutrients $\mathrm{N}, \mathrm{P}, \mathrm{K}$, and $\mathrm{S}$ as well as the micronutrient Fe (not shown). None of 
176 these regressions pointed clearly to a relationship between seedling density and soil temperature

177 or nutrition, having non-significant slopes and poor goodness-of-fit.

\section{Discussion}

The addition of a sparse layer of cone-bearing mulch along with seed supplementation was the most effective treatment both to obtain a high seedling density and to promote an even distribution of the seedlings. The importance of mulch for seedling establishment is eminently clear even without seed supplementation. In the non-seeded condition, seedling density was an order of magnitude greater by having any level of mulch cover on the ground compared to bare soil. The success of establishment in the mulch-covered plots was likely from two reasons: firstly, the non-seeded plots with mulch cover had a large number of seedlings originating from seeds present in whole or shattered cones that were part of the mulch, since the mulch had come from harvest debris with tree tops of lodgepole pine. Secondly, the mulch provided shelter for seedlings especially in the germination phase where roots need to penetrate soil to locate stable water supplies. Shelter and organic soil cover has been shown to be beneficial for conifer establishment (Kemball et al. 2006; Wang et al. 2005), even for shade intolerant species like jack pine (P. banskiana Lamb.). It is likely that the mulch also provided some level of protection against soil erosion during germination. Although the 3 and $5 \mathrm{~cm}$ mulch treatments had more seed delivered to the plots, they showed no significant increases in density or frequency over the $1 \mathrm{~cm}$ thick mulch. Thick mulch layers could in fact be detrimental in relation to the number of microsites suitable for successful germination since there is a higher chance for seeds to remain caught in the mulch material without reaching the soil surface. 
198 Plots corresponding to the non-seeded $0-\mathrm{cm}$ mulch treatment had a few pine seedlings that may 199 have come different sources such as airborne seed from surrounding forests and seed or cone 200 movement from adjacent plots, either by wind or animals. Increasing the seed density with an 201 additional 50,000 seeds per hectare contributed about 5,000 seedlings ha ${ }^{-1}$ when applied to bare 202 soil. Comparatively, seeding onto $1 \mathrm{~cm}$ thick mulch improved seedling density by 10,000 203 seedlings per hectare over the mulch alone, highlighting the benefit to early germination success 204 by the mulch cover on the ground. Similar benefits of increased soil moisture with an organic 205 cover have been reported in relation to various other conifers (Kemball et al. 2006; Wang et al. 206 2005). Indeed roughening the surface layers and providing sheltered microsites has also been 207 shown to increase seeding success in drier environments, particularly when precipitation is 208 below average (Eldridge et al. 2012).

209 The lack of relationship found between seedling density and soil temperature and/or nutrient 210 status, stresses the fact that during the recruitment and seedling establishment phases of the 211 regeneration, the availability of sheltered microsites is perhaps the most important variable 212 within a wide range of conditions. Sheltering may also be important before germination since it 213 lowers the risk of the seed population being predated by birds and small mammals and during 214 seed germination it provides a more stable moisture environment for the radicle to anchor the 215 seedling. As there were about 17,000 natural seedlings in $1 \mathrm{~cm}$ of mulch treatment by year three 216 and density increased to 27,000 with the added seed, our data suggests that the $1 \mathrm{~cm}$ of woody 217 mulch from these pine logging sites added $\sim 85,000$ seeds $\mathrm{ha}^{-1}$, presumably more if a proportion 218 of the seed was retained in the cones. A deficiency of seed in other woody mulches could thereby 219 be made up by the addition of supplementary seed. 
220 The $1 \mathrm{~cm}$ depth of mulch was arguably the most effective at regenerating these pads. This thin

221 layer of mulch was able to deliver a sufficient amount of seed to obtain $\sim 17,000$ seedling by year

222 three and these seedlings were well dispersed based upon the percentage stocking values. The

223 deeper layer of mulch would have had greater amounts of seed but this did not translate to

224 greater seedling density, most likely due to the thicker mulch impeding seedling emergence or

225 successful rooting. Furthermore, in the 1-cm mulch, the higher exposure of mineral soil due to

226 micro-scale gaps between woody mulch pieces allowed germinants to take root right into the

227 mineral soil and LFH mixture, while providing sufficient shade patches such that moisture

228 retention during germination was improved. In the deeper layer of mulch, however, there may be

229 future opportunities for recruitment as the closed cones buried in the mulch may release some

230 viable seed (Teste et al. 2011b) as the covering layers of mulch are decomposed. Hellum and

231 Linfield (1986) noted that recruitment from natural regeneration extended for a decade on pine

232 cutover areas - likely due to this factor.

233 The fact that in the naturally regenerated plots, seedlings were often clustered near the partial or

234 complete cones indicates that cones were an important seed source. As intraspecific competition

235 would eliminate all but one of the seedlings in a cluster, however, the better dispersal of

236 seedlings in the seeded plots would likely translate into reasonable numbers of successful

237 seedlings. Nevertheless, the natural seed in the thin layer of mulch had good numbers of seedling

238 and levels of stocking, without the extra expense of seeding. We estimate that the average cluster

239 consisted of three seedlings per cone, taking into account non-clustered seedlings. If we consider

240 the survival of one out of three seedlings in a cluster, the seedling density after competition

241 would be just under 6,000 seedlings $\mathrm{ha}^{-1}$ in the $1-\mathrm{cm}$ mulch treatment. This is similar to post-fire

242 regeneration density in other lodgepole pine stands (Johnstone et al. 2004). 
243 All levels of mulch cover had about the same mean soil temperature, but plots with mulch 244 showed less diurnal temperature fluctuation than non-covered soil - similar to observations of 245 cover of debris on severely disturbed sites (Bulmer et al. 2007). The cooler temperatures under 246 the mulch also resulted in higher soil moisture due to lower surface temperatures because of the 247 shielding of solar radiation; similar to the coverage of 'hog fuel' in Bulmer et al. (2007). We 248 caution that a single soil water sample (in time) was taken after a period of rain at the end of 249 August of 2014 and, therefore, we can only draw on the one-time link found between mulch and 250 water in this case. However, it is conceivable that thicker layers of mulch might also intercept 251 precipitation thereby actually decreasing soil moisture at depth, during periods with incidence of 252 many cycles of low precipitation. The reduction in temperature extremes under mulch could 253 potentially benefit the seedlings both during colder days and during the night since the mulch can 254 reflect back and re-emit longwave radiation, particularly when wet (Montague et al. 2000).

255 In addition to adding cost and time to the reclamation operations, tilling the mulch into the soil 256 negated any benefits of having a natural seed source for regeneration in the form of cones. The 257 tilling process incorporated the cones into the soil where either the cones remained closed 258 because the cones never experience the $\sim 45^{\circ} \mathrm{C}$ needed to open these serotinous cones, or the 259 seed was buried too deep for the cotyledons to reach the surface. Moreover, incorporation of the 260 mulch left most of the surface as bare soil with little woody debris on the surface to shelter 261 germinants. In addition, the high amount of $\mathrm{C}$ incorporated would have promoted the growth of 262 soil microflora which can create a demand for $\mathrm{N}$ that will generally lower the availability of $\mathrm{N}$ 263 and other nutrients for plant growth (Sanborn et al. 2004). High N availability however, is more 264 likely to be a concern in regards to competition with invasive and noxious weeds, the presence of 265 which was variable across the pads. 
266 In our study the added mulch had little consistent effect on exchangeable nutrient availability

267 except for $\mathrm{Fe}$ and more weakly for $\mathrm{P}$ and $\mathrm{NH}_{4}{ }^{+}$. Greater amounts of $\mathrm{Fe}$ in the exchangeable

268 fraction were found with increasing amount of mulch on the surface. Redox processes in the 269 organic matter are likely responsible for releasing Fe, which then appears in the leachate 270 (Schuman 1988). Tilling drastically reduced available Fe which is consistent with other 271 observations (Schuman 1985). Other studies with added woody chips showed that reduction in $\mathrm{N}$ 272 availability is dependent on the rate of application (Homyak et al. 2008 and references therein).

273 In our study, the mulch was made from tops and branches of lodgepole pine which has normally 274 twice the concentration of $\mathrm{N}$ compared with mulch from large stem material (Wei et al. 1997).

275 The high C:N values noted in wastes containing a large amount of bole material (Bulmer et al. 276 2007) were likely not a big factor with the mulch applied in our study. Incorporation of mulch 277 into the soil might reduce soil bulk density in the future (Sanborn et al. 2004; Bulmer et al. 2007) 278 but it is not clear if this is so when mulch is only spread on the surface. We did not assess the 279 effect of mulch on soil bulk density since the sites were disked as part of the treatment.

280 The higher levels of $\mathrm{NH}_{4}{ }^{+}$observed in the mulch treatments are consistent with wetter, lower 281 temperature conditions where nitrification is less active, while the temperature of the bare plots 282 approached the optimum for nitrification in that area (Malhi and McGill 1982). This is 283 potentially an additional benefit of the mulch to the young seedlings once they are established, 284 since high $\mathrm{NH}_{4}^{+}$(in relation to $\mathrm{NO}_{3}^{-}$) has been associated with faster growth in coniferous 285 species, especially in height (Nelson and Selby 1974; Margolis et al. 1988). Fast-growing 286 seedlings are the key to a favourable competition outcome, and the mulch treatments showed 287 conditions to support both seedling recruitment and early growth better than bare plots. 


\section{Conclusions}

289 Seed management either by spreading of cones or artificial seeding was an effective means of 290 establishing pine seedlings - provided there was a shallow cover of mulch to protect the 291 seedlings. Deeper coverage of the site with mulch provided no additional benefits in the short 292 term. Seedlings may have benefited from greater water supply in the mineral soil that is sheltered 293 by the mulch as suggested by the water content measured at the end of August 2014, and perhaps 294 from reduced erosion undermining anchorage of germinants during the sprouting stage. 295 Mulching improved soil nutrients in a manner that we anticipate will be favourable for pine 296 seedlings. Tilling of mulch into the soil is not recommended as it deeply buried the cones and 297 seed and negated the early positive effects of surface mulch on mineral nutrients.

\section{Acknowledgements}

299 Funding was provided by Devon Canada with matching funding from the Natural Sciences and 300 Engineering Research Council of Canada and Weyerhaeuser for assistance with the source of 301 mulch. We also thank Kevin Stark and Mike Head from Devon and Dave Larson for their 302 assistance in planning and measurements. We also thank Doug Kulba, Logan Purdy, Fran 303 Leishman and Lewis Fausak for assistance. 


\section{References}

306 Beckingham, J. D., Corns, I. G. W., and Archibald J.H. 1996. Field guide to the ecosites of west307 central Alberta. Canadian Forestry Service, Special Report ISSN 1188-7419:9.

308 309

310

Bulmer, C., Venner, K., and Prescott C. 2007. Forest soil rehabilitation with tillage and wood waste enhances seedling establishment but not height after 8 years. Can. J. For. Res. 37:1894-1906.

Campbell, D. B., Bulmer, C. E., Jones, M. D., Philip, L. J. and Zwiazek, J. J. 2008. Incorporating topsoil and burn pile debris substantially increases early growth of lodgepole pine on landings. Can. J. For. Res. 38:257-267.

Corns, I.G.W., and La Roi, G.H. 1976. A comparison of mature with recently clear-cut and scarified lodgepole pine forests in the lower foothills of Alberta. Can. J. For. Res. 6:2032.

Ecological Stratification Working Group. 1996. A National Ecological Framework for Canada. Agriculture and Agri-Food Canada, Research Branch, Centre for Land and Biological Resources Research, and Environment Canada, State of the Environment Directorate, Ecozone Analysis Branch, Ottawa/ Hull. Report and national map at 1:7 500000 scale.

Eldridge, J. D., Redente, E. F. and Paschke, M. 2012. The use of seedbed modifications and wood chips to accelerate restoration of well pad sites in western Colorado, U.S.A. Restor. Ecol. 20:524-531. 
324 Elmarsdottir, A., Aradottir, A. L. and Trlica, M. J. 2003. Microsite availability and establishment 325 of native species on degraded and reclaimed sites. J. Appl. Ecol. 40:815-823.

326 Environment and Sustainable Resource development (ESRD). 2013. Reclamation criteria for wellsites and associated facilities for forested land. Edmonton, AB. 81pp.

328

329

330

331

Government of Canada. 2015. Monthly climate summaries [online]. Available from http://climate.weather.gc.ca/prods servs/cdn climate summary e.html [accessed 21 June 2016]

Hellum, A. K., and Linfield, G. H. 1986. Predictable development of stocking of lodgepole pine in west-central Alberta after drag scarification. Meddelelser fra Norsk Institutt for Skogforskning 39:113-127.

Homyak, P. M., Yanai, R. D., Burns, D. A., Briggs, R. D., and Germain, R. H. 2008. Nitrogen immobilization by wood-chip application: Protecting water quality in a northern hardwood forest. Forest Ecol. Manag. 255:2589-2601.

Johnstone, J. F., Chapin, F. S. III, Foote, J., Kemmett, S., Price, K., and Viereck, L. 2004. Decadal observations of tree regeneration following fire in boreal forests. Can J. For. Res. 34:267-273.

Kemball, K. J., Wang, G., and Westwood A. R. 2006. Are mineral soils exposed by severe wildfire better seedbeds for conifer regeneration? Can. J. For. Res. 36:1943-1950. 
342 Landhäuser, S. M. 2009. Impact of slash removal, drag scarification, and mounding on lodgepole

343 pine cone distribution and seedling regeneration after cut-to-length harvesting on high

$344 \quad$ elevation sites. Forest Ecol. Manag. 258: 43-49.

345 Lanini, W. T., and Radosevich, S. R. 1986. Response of three conifer species to site preparation $346 \quad$ and shrub control. Forest Sci. 32:61-77.

347 Larney, F. J., and Angers, D. A. 2012. The role of organic amendments in soil reclamation: A 348 review. Can. J. Soil Sci. 92:19-38.

349 Malhi, S. S., and McGill, W. B. 1982. Nitrification in three Alberta soils: Effect of temperature, 350 moisture and substrate concentration. Soil Biol. Biochem. 14:393-399.

351 Margolis, H. A., Vezina, L. P., and Ouimet, R. 1988. Relation of light and nitrogen source to 352 353 growth, nitrate reductase and glutamine synthase activity of jack pine seedlings. Physiol. Plantarum 72:790-795.

354 Montague, T., Kjelgren, R., and Rupp, L. 2000. Surface energy balance affects gas exchange and 355 356 growth of two irrigated landscape tree species in an arid climate. J. Amer. Soc. Hort. Sci. 125: 299-309.

Muir, P. S., and Lotan, J. E. 1985. Serotiny and life history of Pinus contorta var. latifolia. Can. J. Bot. 63:938-945.

359 Nelson, L. E., and Selby, R. 1974. The effect of nitrogen sources and iron levels on the growth and composition of Sitka spruce and Scots pine. Plant Soil 41:573-588. 
361 Perry, D. A., and Lotan, J. E. 1977. Opening temperatures in serotinous cones of lodgepole pine. USDA Forest Service, Research Note INT-228.

363

364

365

R Core Team. 2015. R: A language and environment for statistical computing. R Foundation for Statistical Computing, Vienna, Austria [online]. Available from http://www.Rproject.org/ [accessed 29 March 2016]

Sanborn, P. L., Bulmer, C., and Coopersmith, D. 2004. Use of wood waste in rehabilitation of landings constructed on fine-textured soils, central interior BC, Canada. West. J. Appl. For. 19:175-183.

Shuman, L. M., and Hargrove, W. L. 1985. Effect of tillage on the distribution of manganese, copper, iron, and zinc in soil fractions. Soil Sci. Soc. Am. J. 49:1117-1121.

Shuman, L. M. 1988. Effect of organic matter on the distribution of manganese, copper, iron, and zinc in soil fractions. Soil Sci. 146:192-198.

Spiegelberger, T., Müller-Schärer, H., Matthies, D., and Schaffner, U. 2009. Sawdust addition reduces the productivity of nitrogen-enriched mountain grasslands. Restor. Ecol. 17:865872.

Startsev, A. D., and McNabb, D. H. 2009. Effects of compaction on aeration and morphology of boreal forest soils in Alberta, Canada. Can. J. Soil Sci. 89:45-56.

Teste, F. P., Lieffers, V. J., and Landhäusser, S. M. 2011a. Seed release in serotinous lodgepole pine forests after mountain pine beetle outbreak. Ecol. Appl. 21:150-162. 
380 Teste, F. P., Lieffers, V. J., and Landhäusser, S. M. 2011b. Viability of forest floor and canopy

381 seed banks in Pinus contorta var. latifolia (Pinaceae) forests after a mountain pine beetle

382 outbreak. Am. J. Bot. 98:1-8.

383 Wang, G. G., and Kemball, K. J. 2005. Balsam fir and white spruce seedling recruitment in 384 response to understory release, seedbed type, and litter exclusion in trembling aspen 385 stands. Can. J. For. Res. 35:667-673.

386 Wei, X., Kimmins, J. P., Peel, K. and Steen, O. 1997. Mass and nutrients in woody debris in harvested and wildfire-killed lodgepole pine forests in the central interior of British Columbia. Can. J. For. Res. 27:148-155. 
392 supplementation).

\begin{tabular}{lllc}
\hline \multicolumn{1}{c}{ Experiment \# } & $\begin{array}{c}\text { Mulch layer } \\
\text { thickness (cm) }\end{array}$ & Tilling & $\begin{array}{c}\text { Seed } \\
\text { supplementation }\end{array}$ \\
\hline 1: mulch level, 2: seed suppl. & 0 (no mulch) & No & No \\
1: mulch level, 2: seed suppl. & 1 & No & No \\
2: seed suppl. & 0 (no mulch) & No & Yes \\
2: seed suppl. & 1 & No & Yes \\
1: mulch level, 3: tilling & 3 & No & No \\
1: mulch level, 3: tilling & 5 & No & No \\
3: tilling & 3 & Yes & No \\
3: tilling & 5 & Yes & No \\
\hline
\end{tabular}

Table 2. ANOVA results of the three experiments and soil nutrients as affected by mulch depth.

\begin{tabular}{lllll} 
Df & SS & MS & F & p ( $>$ F $)$ \\
\hline
\end{tabular}

Exp. 1. Effect of mulch depth. Response is pine seedling density.

\begin{tabular}{llllll}
\hline Mulch & 3 & $1.182 \times 10^{9}$ & $0.394 \times 10^{9}$ & 5.166 & 0.00676
\end{tabular}

Exp. 2. Effect of seed supplementation with $(1 \mathrm{~cm})$ and without mulch. Response is pine seedling density.

\begin{tabular}{lrrrrrr}
\hline Seeding & 1 & $5.47 \times 10^{9}$ & $5.47 \times 10^{9}$ & 16.505 & 0.00006 \\
Mulch & 1 & $37.54 \times 10^{9}$ & $37.54 \times 10^{9}$ & 113.230 & $<0.00001$ \\
Interaction & 1 & $1.12 \times 10^{9}$ & $1.12 \times 10^{9}$ & 3.366 & 0.06730
\end{tabular}

Exp. 3. Effect of tilling-in two levels of mulch ( 3 and $5 \mathrm{~cm})$. Response is pine seedling density.

$\begin{array}{lrrrrr}\text { Tilling } & 1 & 1382 \times 10^{6} & 1382 \times 10^{6} & 24.728 & \mathbf{0 . 0 0 0 0 4} \\ \text { Mulch } & 1 & 29 \times 10^{6} & 29 \times 10^{6} & 0.519 & 0.47800 \\ \text { Interaction } & 1 & 31 \times 10^{6} & 31 \times 10^{6} & 0.564 & 0.46000\end{array}$

Effects of mulch depth on different nutrients. Statistics correspond to factor mulch at 4 levels.

\begin{tabular}{|c|c|c|c|c|c|}
\hline Response & & & & & \\
\hline $\mathrm{N}$ & 3 & 40.4 & 13.5 & 2.222 & 0.11050 \\
\hline $\mathrm{NH}_{4}^{+}$ & 3 & 24.3 & 8.1 & 4.760 & 0.00893 \\
\hline $\mathrm{P}$ & 3 & 84.4 & 28.1 & 2.203 & 0.10990 \\
\hline K & 3 & 345.1 & 115.0 & 0.394 & 0.75840 \\
\hline $\mathrm{Fe}$ & 3 & 1507256.0 & 502419.0 & 7.447 & 0.00081 \\
\hline
\end{tabular}

p-values $<0.05$ appear in bold type 
396 Table 3. Soil nutrient levels of all treatment plots $\left(\mu \mathrm{g} \mathrm{cm}^{-2}\right.$ at $10 \mathrm{~cm}$ depth for an 80 day period).

397 Plots that were tilled are included for comparison but they do not form part of the ANOVA since

398 they belong to a different experiment. Numbers in parenthesis indicate standard errors. Different

399 letters indicate statistical differences within the same column $(\mathrm{p}<0.05)$.

\begin{tabular}{ccrlllllllll}
\hline $\begin{array}{c}\text { Cover } \\
(\mathrm{cm})\end{array}$ & $\begin{array}{c}\text { Tilling } \\
(\text { Yes/No) }\end{array}$ & \multicolumn{1}{c}{$\mathrm{N}$} & \multicolumn{1}{c}{$\mathrm{NH}_{4}^{+}$} & \multicolumn{1}{c}{$\mathrm{P}$} & $\mathrm{K}$ & \multicolumn{3}{c}{$\mathrm{Fe}$} \\
\hline 0 & $\mathrm{~N}$ & 10.4 & $(3.3)$ & 3.5 & $(0.4)^{\mathrm{b}}$ & 2.70 & $(0.7)$ & 24.0 & $(4.2)$ & 137 & $(51)^{\mathrm{c}}$ \\
1 & $\mathrm{~N}$ & 9.1 & $(2.5)$ & 4.6 & $(0.5)^{\mathrm{ab}}$ & 4.97 & $(1.2)$ & 28.4 & $(4.8)$ & 453 & $(99)^{\mathrm{b}}$ \\
3 & $\mathrm{~N}$ & 10.0 & $(1.3)$ & 5.9 & $(0.7)^{\mathrm{ab}}$ & 4.55 & $(1.5)$ & 29.5 & $(9.9)$ & 429 & $(93)^{\mathrm{b}}$ \\
5 & $\mathrm{~N}$ & 8.0 & $(0.8)$ & 5.4 & $(0.5)^{\mathrm{a}}$ & 7.26 & $(1.5)$ & 21.4 & $(1.7)$ & 751 & $(84)^{\mathrm{a}}$ \\
\hline 3 & $\mathrm{Y}$ & 7.3 & $(2.5)$ & 2.7 & $(0.2)$ & 2.66 & $(0.5)$ & 32.9 & $(5.2)$ & 79 & $(28)$ \\
5 & $\mathrm{Y}$ & 10.8 & $(2.1)$ & 3.4 & $(0.5)$ & 2.85 & $(0.7)$ & 23.9 & $(3.5)$ & 92 & $(25)$ \\
\hline
\end{tabular}




\section{List of Figures}

403 Figure 1. Seedling density in plots with different levels of mulch cover and without tilling. Error

404 bars indicate standard error. Different letters indicate statistically significant differences within

405 the same year $(\mathrm{p}<0.05)$.

Figure 2. Seedling density in seeded and non-seeded plots without cover and with 1-cm nominal

407 cover level. Error bars indicate standard error. Different letters indicate statistically significant

408 differences $(\mathrm{p}<0.05)$ with comparisons being performed within cover level (not between levels).

409 Figure 3. Frequency of sampling plots with at least one seedling (\% stocking). Plots of all

410 treatment levels are represented including seeded plots (0S: no cover, seeded; 1S: 1-cm chip

411 cover, seeded). Gray levels are included for visual separation of cover levels: bars with the same

412 color belong to the same level of mulch cover. Error bars indicate standard error. Different letters

413 indicate statistically significant differences $(\mathrm{p}<0.05)$.

414 Figure 4. Soil daily mean temperature of plots with surface mulch (dashed line) and bare (solid

415 line) plots during a two-month span. On some days, maximum and minimum temperatures are

416 displayed to compare thermal amplitudes ('*'symbols for covered, '+' symbols for non-covered);

417 these points represent local maxima and minima. Measurements were taken at a depth of $10 \mathrm{~cm}$

418 from the surface of the soil.

419 Figure 5. Soil water content of bare plots and all mulch cover treatments. Letters indicate small 420 differences between covered and non-covered $(0.05<\mathrm{p}<0.1)$. Soil samples of the first 10 to 15

$421 \mathrm{~cm}$ of soil (excluding mulch) were collected August $27^{\text {th }}, 2014$. 


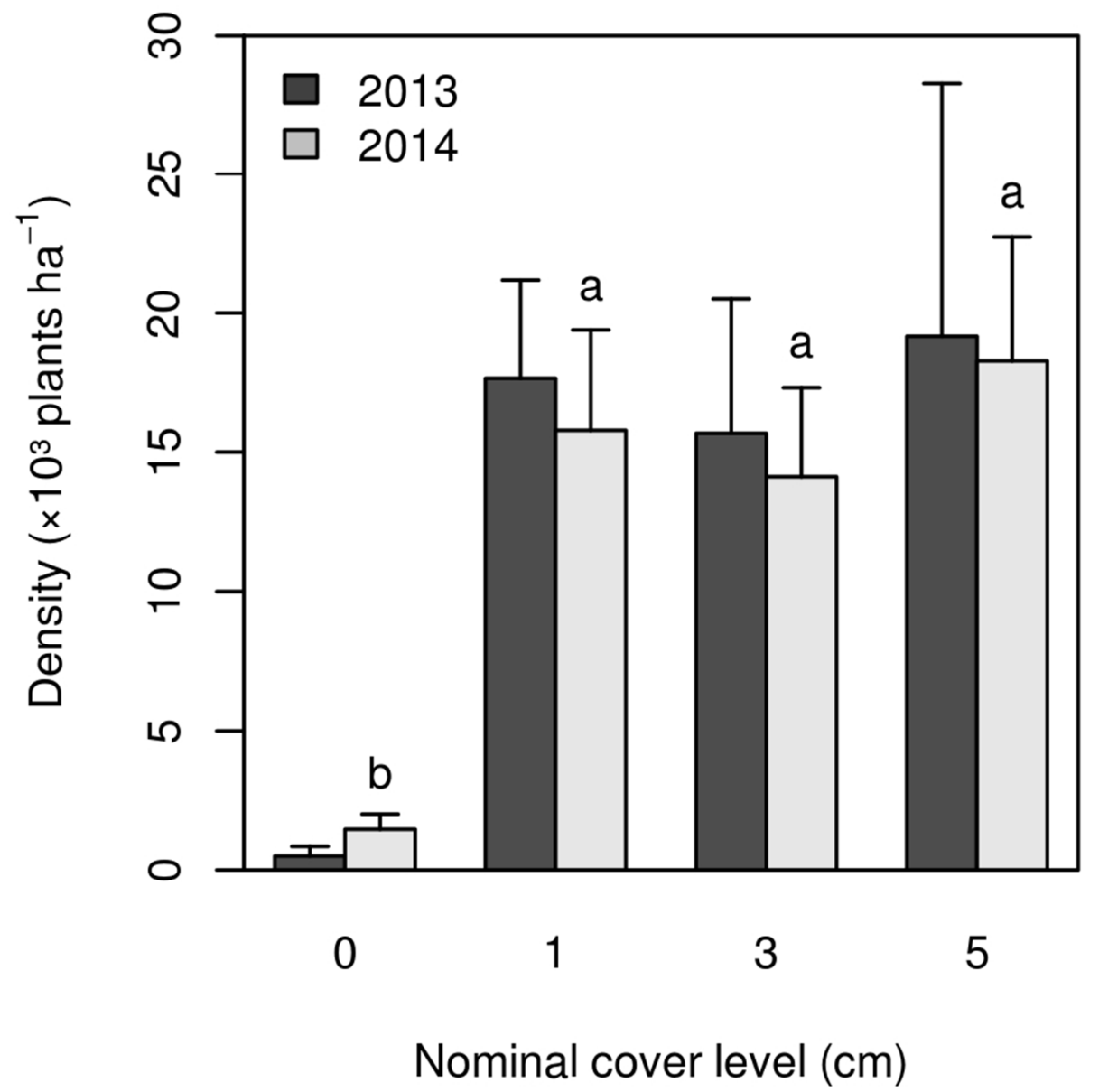

Seedling density in plots with different levels of mulch cover and without tilling. Error bars indicate standard error. Different letters indicate statistically significant differences within the same year $(p<0.05)$. 


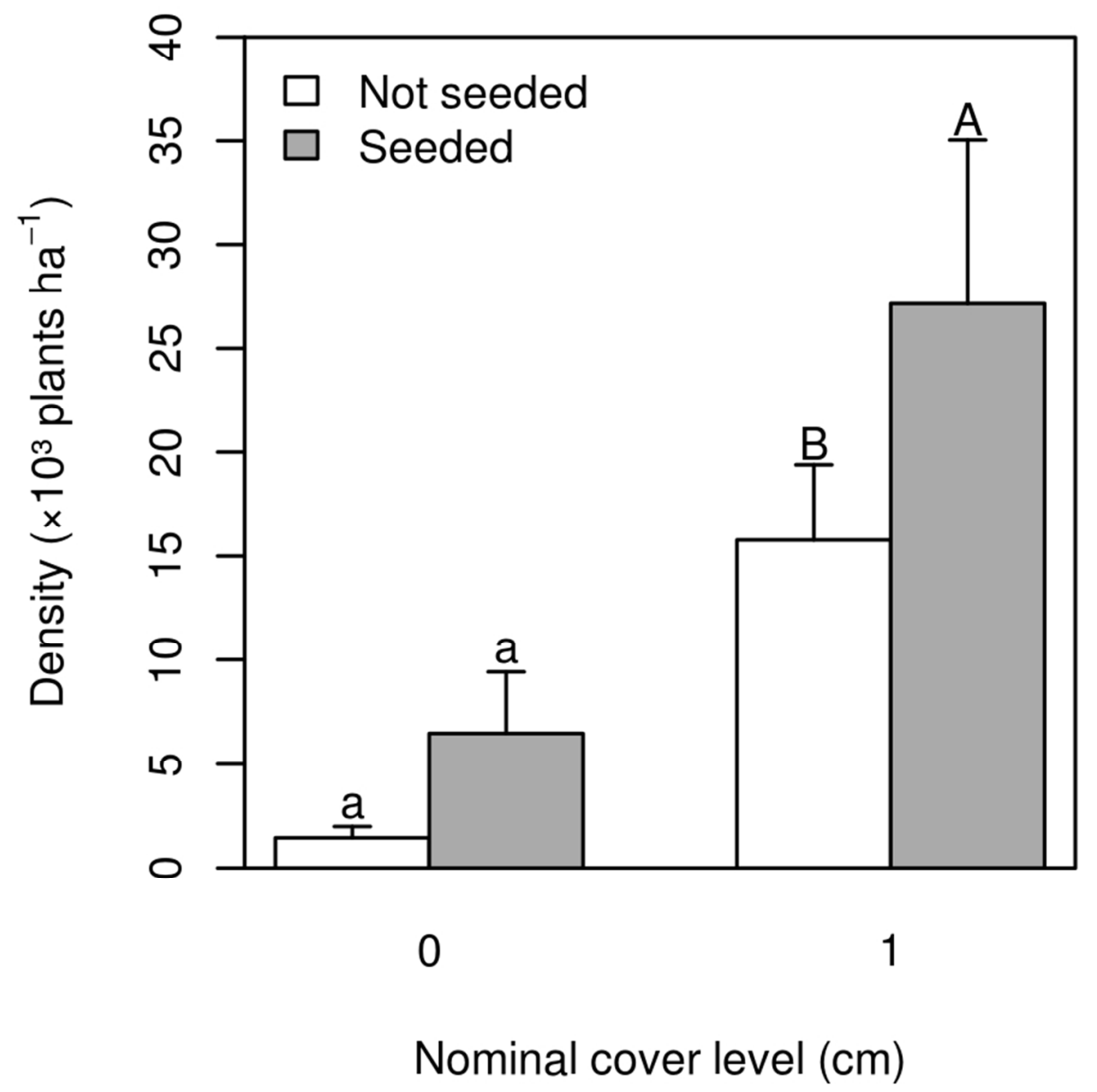

Seedling density in seeded and non-seeded plots without cover and with 1 -cm nominal cover level. Error bars indicate standard error. Different letters indicate statistically significant differences $(p<0.05)$ with comparisons being performed within cover level (not between levels). 


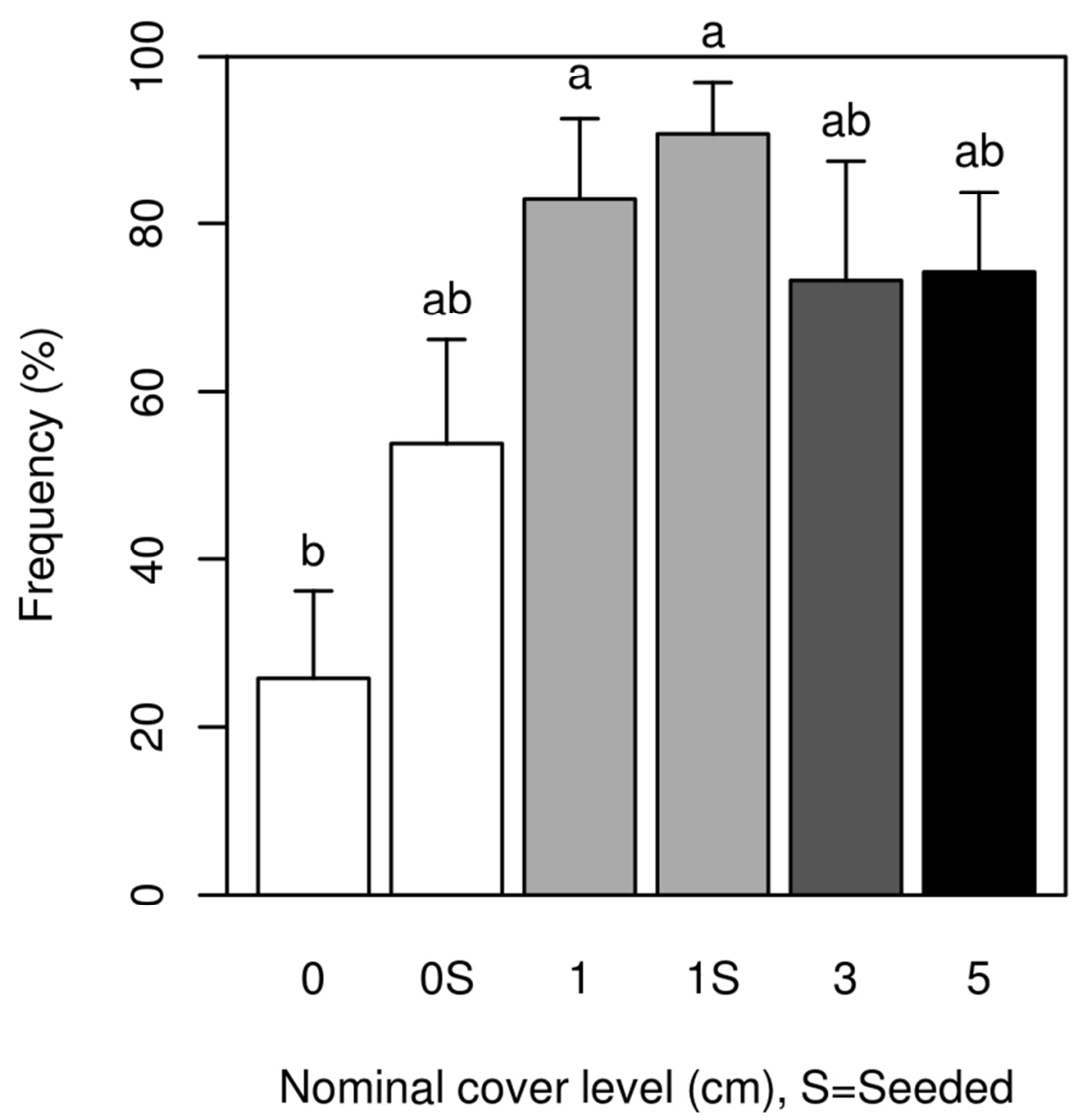

Frequency of sampling plots with at least one seedling (\% stocking). Plots of all treatment levels are represented including seeded plots (0S: no cover, seeded; $1 \mathrm{~S}$ : 1 -cm chip cover, seeded). Gray levels are included for visual separation of cover levels: bars with the same color belong to the same level of mulch cover. Error bars indicate standard error. Different letters indicate statistically significant differences ( $p<$ 0.05). 


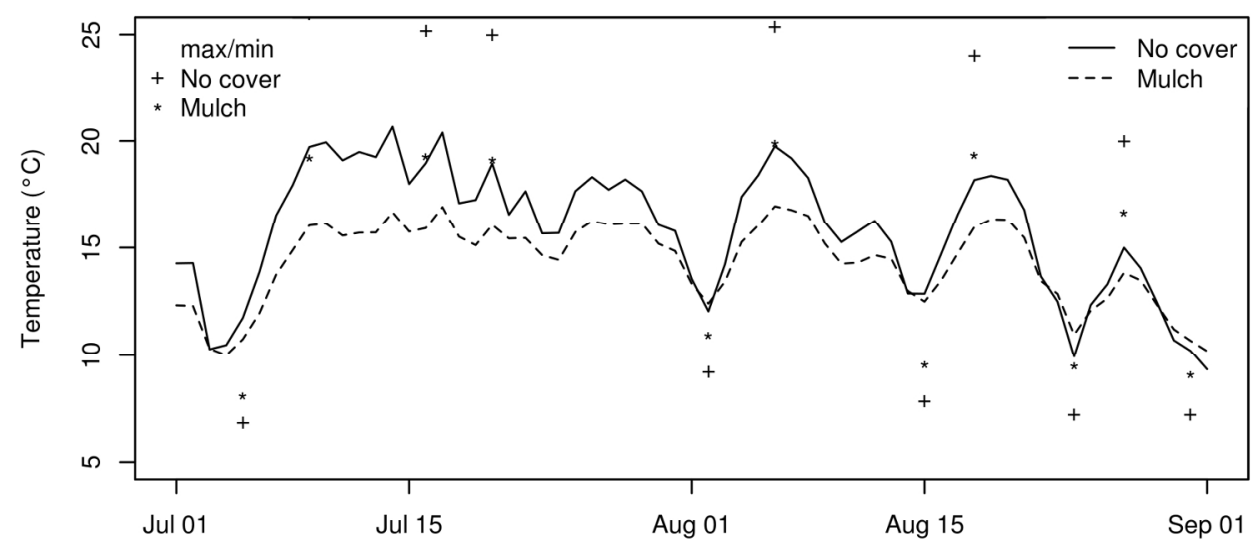

Soil daily mean temperature of plots with surface mulch (dashed line) and bare (solid line) plots during a two-month span. On some days, maximum and minimum temperatures are displayed to compare thermal amplitudes ('*'symbols for covered, ' + ' symbols for non-covered); these points represent local maxima and minima. Measurements were taken at a depth of $10 \mathrm{~cm}$ from the surface of the soil. 


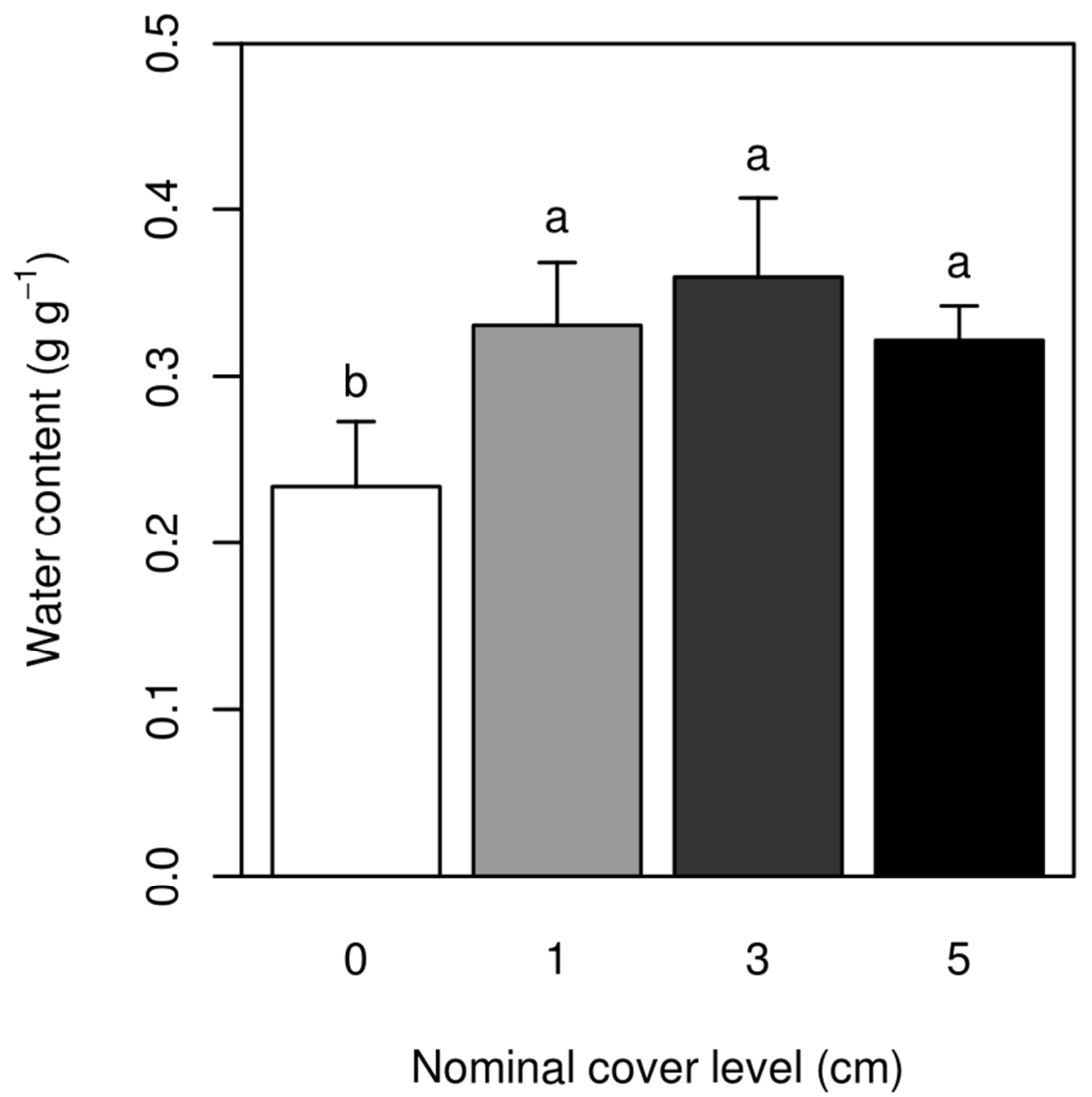

Soil water content of bare plots and all mulch cover treatments. Letters indicate small differences between covered and non-covered $(0.05<\mathrm{p}<0.1)$. Soil samples of the first 10 to $15 \mathrm{~cm}$ of soil (excluding mulch) were collected August 27th, 2014. 